\title{
The Negative Impact of Tobacco Smoking on Health-Related Quality of Life among Saudi Adolescents During the COVID-19 Pandemic
}

\author{
Mohammed Sheker H Al-Kalif ${ }^{1 *}$, Amal A Alghamdi², Faisal M Albagmi ${ }^{3}$, \\ Ali Hassan A Alnasser ${ }^{4 *}$
}

\begin{abstract}
Objective: This study aimed to evaluate the impact of cigarette smoking and health-related quality of life among Saudi secondary vocational students during the COVID-19 pandemic. Methods: A convenience sample of 328 answered a web-based self-administered questionnaire based on the Youth Risky Behavior Monitoring System (YRBSS) plus the Short Form 12 (SF-12) were included in the study. The target population included all Saudi students enrolled at the Secondary Industrial Institute in Dammam, Saudi Arabia, during December 2020 and February 2021. Results: Out of the total of 328 male participants, representing a response rate of $38.59 \%$, the highest percentage of respondents were in the first year (45.4\%), the mean age of the participants was 17.73 years with a standard deviation (SD) of 1.85 years. The prevalence of current smokers, past smokers, and never smokers accounted for $30.2 \%, 21.3 \%$, and $48.5 \%$, respectively. First-year students reported relatively high levels of smoking prevalence and low physical scores of healthrelated quality of life (HRQoL). The overall mean of HRQoL of current smokers, past smokers, and never smokers accounted for $58.60,58.38$, and 63.66 , respectively. In addition, current smokers reported a relatively low physical score of HRQoL 55.73. Conclusion: This is the first report to explore the impact of smoking on HRQoL of Secondary Industrial Institute students in Saudi Arabia during the COVID-19 pandemic. The results indicate that smoking has a negative impact on the quality of life of vocational students. Therefore, a health strategies plan may be developed to improve the quality of life for vocational students in Saudi Arabia.
\end{abstract}

Keywords: Cigarette's smoking- smoking prevalence- smoking risk factors- tobacco products- smoking habits

Asian Pac J Cancer Prev, 22 (12), 4051-4056

\section{Introduction}

Smoking is causing around 8 million deaths annually and more than 1.2 million cases indirectly and $85 \%$ directly attributable to tobacco use (WHO, 2020). Consequently, smoking causes damage to the global economy, which costs hundreds of billions of dollars annually (Gaffar et al., 2013). The COVID-19 pandemic had a massive impact on human health, particularly young people and children worldwide (Jiao et al., 2020). Also, the COVID-19 pandemic has had a negative impact associated with increased smoking rates (Vardavas and Nikitara, 2020). Smoking among adolescents worldwide is estimated to be 150 million (Abdulmohsen Hamdan et al., 2015). Additionally, smoking-related illnesses can cause the premature death of more than 6 million adolescents ( $\mathrm{Al}$ Ghobain et al., 2011). In 2012, the prevalence of tobacco product use among American middle school students and American high school students was estimated at $6.7 \%$ and $23.3 \%$, respectively (Hourani et al., 2017). In 2000, Saudi Arabia rose to become one of the world's top ten cigarette importers (Abdulmohsen Hamdan et al., 2015). According to statistics, the smoking rate among Saudi adolescents has progressively expanded from $12.45 \%$ in 2000 to $15.1 \%$ in 2010 (Alasqah et al., 2019). In Saudi Arabia, the prevalence of smoking among males and females aged 16 to 18 is estimated to be $55.6 \%$ and $31.4 \%$, respectively ( $\mathrm{Al}$ Ghobain et al., 2011). It should be noted that Saudi male adolescents are more likely to smoke than Saudi female adolescents. According to a systematic review, between 2007 and 2018, the prevalence of tobacco smoking among Saudi adolescents ranged from $2.4 \%$ to $39.6 \%$ (Alasqah et al., 2019). There are regional differences in the prevalence of current smokers among adolescents in Saudi secondary

${ }^{I}$ Department of Public Health, College of Public Health, Imam Abdulrahman Bin Faisal University Technical and Vocational Training Corporation, Riyadh, Saudi Arabia. ${ }^{2}$ Department of Family and Community Medicine, College of Medicine, Imam Abdulrahman Bin Faisal University, Dammam, Saudi Arabia. ${ }^{3}$ Department of Physical Therapy, College of Applied Medical Sciences, Imam Abdulrahman Bin Faisal University, Dammam, Saudi Arabia. ${ }^{4}$ Department of Laboratory, Dhahran Eye Specialist Hospital, Ministry of Health, Dhahran, Saudi Arabia.*For Correspondence: moudshk@gmail.com, alialnassser@gmail.com 
schools (Gaffar et al., 2013).

One of the essential components of public health monitoring that affects the relationship between physical and mental health is health-related quality of life (HRQoL) (WHO, 2012; CDC, 2018). Previous studies have shown a negative effect of smoking on HRQoL (López-Nicolás et al., 2018; Milic et al., 2020). In addition, previous research has revealed that smoking has a negative impact on HRQoL in adolescence (Dube et al., 2013; Hourani et al., 2017). However, in Saudi Arabia, cigarette Smoking and HRQoL among secondary vocational students relationships are inadequate investigations. Therefore, the study aimed to determine the impact of cigarette smoking on HRQoL among Saudi secondary vocational students.

\section{Materials and Methods}

\section{Study area, design, and period}

This web-based cross-sectional survey was conducted at the Secondary Industrial Institute in Dammam, Saudi Arabia, from December 28, 2020, to February 1, 2021.

\section{Study participants}

The study included a convenience sample of 328 Saudi male students who attended the Secondary Industrial Institute in Dammam were included in the study.

\section{Questionnaire designed}

The questionnaire is available in Arabic. The questionnaire is provided to the students as a self-evaluation online survey after obtaining the students' consent. The questionnaire consists of three parts: sociodemographic, smoking behavior, and HRQoL. The first part of the questionnaire includes students' sociodemographic variables and smoking behavior variables. The second part of the questionnaire included a smoking assessment conducted through the Youth Risky Behavior Monitoring System (YRBSS) (CDC, 2020b). The third part of the questionnaire consists of HRQoL evaluation achieved using the Short Form 12 Item (SF12) Questionnaire (29). The cigarette smoking evaluation was classified as the following risks: Past smokers as "ever tried a cigarette (even one or two puffs) excluded currently smokers," and currently smoked cigarettes "on at least 1 day during the 30 days before the survey" (CDC, 2019). The YRBSS questionnaires were translated into the Arabic language through WHO's translation methods (WHO).

Short Form 12 (SF12) is a generic measure of HRQoL and a shortened version of SF36. The SF12 has 12 questions that enable the measurement of 8 dimensions of health: bodily pain, general health, physical functioning, role -physical, as well as mental health, role-emotional, vitality, and social functioning. The scores range from 0 to 100 , with a higher score in each dimension reflecting enhanced wellbeing, as perceived by the respondent. The mean score value of the first four fields results in the physical composite score, while that of the last four fields produces the mental composite score. The cumulative score is eventually determined as the physical composite score (PCS) and mental composite score (MCS) sum. The single field score is standardized to a mean of 50 and a standard deviation of 10 . A score greater than 50 indicates better-than-average health, while a score less than 50 indicates poorer-than-average health. SF12 has been previously used in Arabic and showed satisfactory reliability and internal consistency $(\alpha=0.79-0.84)(33,34)$.

A pilot study was conducted to collect data from 33 randomly selected subjects of the same age group from the target population for testing and verification, including surface and content validity and administrative feasibility, and assess the understanding and reliability of the internal consistency of the translated questionnaire. Cronbach's $\alpha$ coefficient was used to estimate the reliability of the internal consistency of the YRBSS questionnaire was internal consistency $(\alpha=0.73)$, the SF12 questionnaire was internal consistency $(\alpha=0.72)$, and the general questionnaire was internal consistency $(\alpha=0.66)$. The response from the preliminary study is not included in the final study results.

\section{Data collection tools and procedure}

The study used a convenient sampling method and collected data using a web-based survey via Google Forms. The questionnaire is systematically sent to all levels of students by teachers and supervisors using the student's phone number. Considering the research population, the total number of students at the Secondary Industrial Institute in Dammam is 850 (GaStat, 2015). The sample size is calculated using open-source public health epidemiological statistics (OpenEpi). The adjusted confidence level is $95 \%$, the margin of error is $5 \%,(50 \%)$ the frequency of appearance of the resulting factor and the recommended sample size of the design effect obtained is 318 students, consider adding ( $20 \%$ ) as non-response rate (OpenEpi).

\section{Statistical Analysis}

Continuous variables were described by mean $(\overline{\mathrm{x}})$, stranding deviation (SD). Spearman correlation coefficient was used to determine the outcome variable of HRQoL. $\mathrm{P}$-value $<0.05$ was considered statistically significant. The statistical package (SPSS v.23) was used for analysis.

\section{Results}

Sociodemographic characteristics of the study population

Among the 328 students, the average age of the study sample was $17.73(\mathrm{SD}=1.85)$; students who were 18 years old were more currently smokers 70 (21.3\%). Of which 149 (45.4\%) were mainly in the first year, $148(45.1 \%)$ their father had a secondary or vocational education, 250 (76.2\%) their father was employed, and $152(46.3 \%)$ had a monthly income of family $<5000$ SR (Table 1).

\section{Prevalence of cigarette smoking among students}

Out of the 328 students, more than half of the 169 students $(51.5 \%)$ were considered as smokers; more than a fifth $(21.3 \%)$ of the students were considered as past smokers, approximately one third $(30.2 \%)$ of the study respondents were considered as current smokers (Table 1). 
Table 1. Description of Sociodemographic Characteristics by Smoking Status $(n=328)$.

\begin{tabular}{|c|c|c|c|c|c|}
\hline \multirow{3}{*}{ Variables } & \multirow{3}{*}{ N (\%) } & \multicolumn{3}{|c|}{ Total smokers $\mathrm{N}=169(51.5 \%)$} & \multirow[t]{3}{*}{ rs $(\mathrm{P})$} \\
\hline & & Never & Past & Current & \\
\hline & & $\mathrm{N}=159(48.5 \%)$ & $\mathrm{N}=70(21.3 \%)$ & $\mathrm{N}=99(30.2 \%)$ & \\
\hline \multicolumn{6}{|l|}{ Age group } \\
\hline \multicolumn{6}{|l|}{$(\overline{\mathrm{x}}=17.73 \pm \mathrm{SD}=1.85)$} \\
\hline$<18$ & $246(75)$ & $119(36.3)$ & $57(17.4)$ & $70(21.3)$ & $0.027(0.630)$ \\
\hline$\geq 18$ & $82(25)$ & $40(12.2)$ & $13(4.0)$ & $29(8.8)$ & \\
\hline \multicolumn{6}{|l|}{ Year of study } \\
\hline First-year & $149(45.4)$ & $66(20.12)$ & $36(10.98)$ & $47(14.33)$ & $-0.023(0.682)$ \\
\hline Second-year & $122(37.2)$ & $68(20.73)$ & $24(7.32)$ & $30(9.15)$ & \\
\hline Third year & $57(17.4)$ & $25(7.62)$ & $10(3.05)$ & $22(6.71)$ & \\
\hline \multicolumn{6}{|l|}{ Father's education level } \\
\hline Less than secondary & $119(36.3)$ & $52(15.85)$ & $25(7.62)$ & $42(12.80)$ & $-0.086(0.121)$ \\
\hline Secondary /Vocational training & $148(45.1)$ & $75(22.87)$ & $31(9.45)$ & $42(12.80)$ & \\
\hline University and above & $61(18.6)$ & $32(9.76)$ & $14(4.27)$ & $15(4.57)$ & \\
\hline \multicolumn{6}{|l|}{ Mother's education level } \\
\hline Less than secondary & $149(45.4)$ & $78(23.78)$ & $28(8.54)$ & $43(13.11)$ & $0.048(0.386)$ \\
\hline Secondary & $117(117)$ & $51(15.55)$ & $30(9.15)$ & $36(10.98)$ & \\
\hline University and above & $62(18.9)$ & $30(9.15)$ & $12(3.66)$ & $20(6.10)$ & \\
\hline \multicolumn{6}{|l|}{ Father's employment status } \\
\hline Unemployed & $52(15.9)$ & $34(10.37)$ & $6(1.83)$ & $12(3.66)$ & $0.036(0.512)$ \\
\hline Employed & $250(76.2)$ & $108(32.93)$ & $58(17.68)$ & $84(25.61)$ & \\
\hline Other & $26(7.9)$ & $17(5.18)$ & $6(1.83)$ & $3(0.91)$ & \\
\hline \multicolumn{6}{|l|}{ Mother's employment status } \\
\hline Unemployed & $236(72.0)$ & $112(34.15)$ & $56(17.07)$ & $68(20.73)$ & $-0.006(0.911)$ \\
\hline Employed & 85 (25.9) & $42(12.80)$ & $13(3.96)$ & $30(9.15)$ & \\
\hline Other & $7(2.1)$ & $5(1.52)$ & $1(0.30)$ & $1(0.30)$ & \\
\hline \multicolumn{6}{|l|}{ Monthly family income } \\
\hline$<5000 \mathrm{SR}$ & $152(46.3)$ & $73(22.26)$ & $30(9.15)$ & $49(14.94)$ & $-0.047(0.399)$ \\
\hline 5000-9999 SR & $94(28.7)$ & $43(13.11)$ & $20(6.10)$ & $31(9.45)$ & \\
\hline$>10000 \mathrm{SR}$ & $82(25.0)$ & $43(13.11)$ & $20(6.10)$ & $19(5.79)$ & \\
\hline
\end{tabular}

\section{Health-related quality of life}

Table 2 shows the overall mean of HRQoL, students who smoked in the past $58.38 \pm 13.20$ were lower than students who had never smoked $63.66 \pm 13.90$. In addition, there is a statistically significant correlation between smoking and HRQoL. The HRQoL mean of current smokers was $58.60 \pm 16.28$ lower than nonsmokers 63.66 \pm 13.90 . First-year students reported relatively high levels of smoking prevalence and low physical scores of healthrelated quality of life (HRQoL). Current smokers reported a relatively low physical score of HRQoL (55.73). There is no statistically significant correlation between cigarette smoking and sociodemographic variables (Table 3).

\section{Discussion}

The present study evaluated the impact of cigarette smoking on health-related quality of life (HRQoL) among Saudi secondary vocational students during the COVID-19 pandemic and used a shortened (SF-12) HRQoL instrument. To our best knowledge, this is the first assessment of the impact of smoking on HRQoL among

Table 2. Correlation between HRQoL Domains and Cigarette Smoking Status ( $\mathrm{N}=328)$.

\begin{tabular}{|c|c|c|c|c|c|c|c|}
\hline \multirow{2}{*}{$\begin{array}{l}\text { Smoking } \\
\text { status }\end{array}$} & \multirow{2}{*}{$\begin{array}{l}\text { Total } \\
\text { N (\%) }\end{array}$} & \multicolumn{2}{|c|}{ HRQoL } & \multicolumn{2}{|c|}{ PCS } & \multicolumn{2}{|c|}{ MCS } \\
\hline & & $\overline{\mathrm{x}} \pm \mathrm{SD}$ & rs $(\mathrm{P})$ & $\overline{\mathrm{x}} \pm \mathrm{SD}$ & rs $(\mathrm{P})$ & $\overline{\mathrm{x}} \pm \mathrm{SD}$ & rs $(\mathrm{P})$ \\
\hline Never & $159(48.5)$ & $63.66 \pm 13.90$ & $-.0181(0.001) * *$ & $61.74 \pm 17.06$ & $-0.152(0.006) * *$ & $65.58 \pm 14.78$ & $-0.128(0.021) *$ \\
\hline Past & $70(21.3)$ & $58.38 \pm 13.20$ & & $59.13 \pm 18.66$ & & $57.63 \pm 16.79$ & \\
\hline Current & 99 (30.2) & $58.60 \pm 16.28$ & & $55.73 \pm 20.19$ & & $61.46 \pm 18.63$ & \\
\hline
\end{tabular}

**, Significant at less than 0.01 level (2-tailed); *, Significant at less than 0.05 level (2-tailed); $\overline{\mathrm{x}}$, mean; SD, standard deviation; rs,Spearman correlation coefficient; P, p-value; HRQOL, Health-related quality of life; PCS, Physical composite score; MCS, Mental composite score 
Table 3. Sociodemographic Factors Correlation with HRQol Domains (N=328).

\begin{tabular}{|c|c|c|c|c|c|c|c|}
\hline \multirow{2}{*}{$\begin{array}{l}\text { Total } \\
\text { Sociodemographic variables }\end{array}$} & \multirow[t]{2}{*}{$\mathrm{N}(\%)$} & \multicolumn{6}{|c|}{$\overline{\mathrm{x}} \pm \mathrm{SD}, \mathrm{rs}(\mathrm{P})$} \\
\hline & & \multicolumn{2}{|c|}{ HRQoL } & \multicolumn{2}{|c|}{ PCS } & \multicolumn{2}{|c|}{ MCS } \\
\hline \multicolumn{8}{|l|}{$\begin{array}{l}\text { Age group } \\
(\overline{\mathrm{x}}=17.73 \pm \mathrm{SD}=1.85)\end{array}$} \\
\hline$<18$ & $246(75 \%)$ & $61.29 \pm 14.75$ & $-0.037(0.505)$ & $59.49 \pm 18.62$ & $-0.016(0.771)$ & $63.09 \pm 16.75$ & $-0.044(0.422)$ \\
\hline$\geq 18$ & $82(25 \%)$ & $60.14 \pm 14.63$ & & $58.99 \pm 18.33$ & & $61.30 \pm 16.61$ & \\
\hline \multicolumn{8}{|l|}{ Year of study } \\
\hline First-year & $149(45.4)$ & $60.10 \pm 13.67$ & $0.052(0.350)$ & $58.15 \pm 18.18$ & $0.078(0.158)$ & $62.05 \pm 15.98$ & $0.009(0.876)$ \\
\hline Second-year & $122(37.2)$ & $61.91 \pm 14.83$ & & $60.20 \pm 17.98$ & & $63.61 \pm 17.37$ & \\
\hline Third year & $57(17.4)$ & $61.45 \pm 17.01$ & & $60.77 \pm 20.58$ & & $62.13 \pm 17.32$ & \\
\hline \multicolumn{8}{|l|}{ Father's education } \\
\hline Less than secondary & $119(36.3)$ & $59.97 \pm 14.64$ & $0.028(0.617)$ & $57.43 \pm 18.59$ & $0.054(0.333)$ & $62.51 \pm 16.60$ & $-0.026(0.640)$ \\
\hline Secondary & $148(45.1)$ & $62.49 \pm 15.10$ & & $61.33 \pm 18.39$ & & $63.65 \pm 16.74$ & \\
\hline University and above & $61(18.6)$ & $59.42 \pm 13.70$ & & $58.38 \pm 18.52$ & & $60.45 \pm 16.88$ & \\
\hline \multicolumn{8}{|l|}{ Mother's education } \\
\hline Less than secondary & $149(45.4)$ & $61.54 \pm 14.60$ & $-0.042(0.445)$ & $59.57 \pm 18.48$ & $-0.022(0.690)$ & $63.50 \pm 17.33$ & $-.062(.261)$ \\
\hline Secondary & 117 (117) & $61.10 \pm 15.08$ & & $59.87 \pm 18.56$ & & $62.33 \pm 16.11$ & \\
\hline University and above & $62(18.9)$ & $59.53 \pm 14.37$ & & $57.92 \pm 18.79$ & & $61.15 \pm 16.42$ & \\
\hline \multicolumn{8}{|l|}{ Father's job } \\
\hline Unemployed & $52(15.9)$ & $63.14 \pm 16.37$ & $-0.027(0.628)$ & $61.51 \pm 19.80$ & $-0.040(0.467)$ & $64.76 \pm 17.08$ & $-0.027(0.622)$ \\
\hline Employed & $250(76.2)$ & $60.54 \pm 14.28$ & & $58.96 \pm 18.36$ & & $62.11 \pm 16.60$ & \\
\hline Other & $26(7.9)$ & $61.25 \pm 15.42$ & & $58.99 \pm 17.82$ & & $63.51 \pm 17.29$ & \\
\hline \multicolumn{8}{|l|}{ Mother's job } \\
\hline Unemployed & $236(72.0)$ & $61.42 \pm 14.67$ & $-0.050(0.370)$ & $60.03 \pm 18.53$ & $-0.069(0.214)$ & $62.81 \pm 16.68$ & $-0.024(0.664)$ \\
\hline Employed & $85(25.9)$ & $60.29 \pm 15.16$ & & $58.46 \pm 18.90$ & & $62.12 \pm 16.84$ & \\
\hline Other & $7(2.1)$ & $55.63 \pm 9.74$ & & $48.04 \pm 7.83$ & & $63.21 \pm 18.48$ & \\
\hline \multicolumn{8}{|l|}{ Monthly Income } \\
\hline$<5000 \mathrm{SR}$ & $152(46.3)$ & $60.05 \pm 14.75$ & $0.082(0.136)$ & $58.89 \pm 18.15$ & $0.035(0.530)$ & $61.22 \pm 17.69$ & $0.076(0.168)$ \\
\hline 5000-9999 SR & $94(28.7)$ & $61.48 \pm 13.94$ & & $59.48 \pm 18.34$ & & $63.48 \pm 15.36$ & \\
\hline$>10000 \mathrm{SR}$ & $82(25.0)$ & $62.22 \pm 15.52$ & & $60.12 \pm 19.59$ & & $64.31 \pm 16.27$ & \\
\hline
\end{tabular}

$\overline{\mathrm{x}}$, mean; SD, standard deviation; rs, Spearman correlation coefficient; P, p-value; HRQOL, Health-related quality of life; PCS, Physical composite score; MCS, Mental composite score

Saudi secondary vocational students during the COVID-19 pandemic. We found that HRQoL was impaired among smokers' students than in nonsmokers' students, according to the SF-12. Additionally, we found that HRQoL is not associated with sociodemographic factors such as age. Furthermore, according to the current study, the high rate of smoking among Saudi adolescents can be attributed to a number of factors, including, but not limited to, student smokers have less intention to quit smoking, difficulty quitting nicotine addiction, lack of readiness to quit smoking, and the low success rate of existing smoking cessation programs (Abdulmohsen Hamdan et al., 2015). Iceland's report notes that adolescents aged 16-18 are the most affected by symptoms of depression and mental well-being during the COVID-19 pandemic but a decline in cigarette smoking, e-cigarette use, and alcohol intoxication among 15-18-year-old adolescents during the COVID-19 pandemic (Thorisdottir et al., 2021). In this study, 9 of the 20 students in the sample are freshmen. Due to the expansion of vocational training, the number of students admitted has increased in recent years (TVTC, 2020).
Our research shows a statistically significant relationship between smoking and HRQoL. Parallel to previous studies, HRQoL is significantly associated with smoking (Dube et al., 2013; Hourani et al., 2017). Our findings support the finding of Shanta R. Dube et al. (2013) of 4,848 American adolescents 12 to 17 years of age that smokers are more likely to have a low HRQoL than nonsmokers (Dube et al., 2013). Furthermore, a Jordanian study found that among 354 Jordanian students aged 10 to 19 , nonsmokers had a higher HRQoL than smokers (Hourani et al., 2017). The mean HRQoL of students is $61.00 \pm 14.71$. Therefore, Suzanne J. van den Toren et al. (2019), in their article on vocational students from 16 to 26 years old in the Netherlands, the average HRQoL is 48.3 (van den Toren et al., 2019). Although, previous studies evaluated the average HRQoL of adolescents between 62.0 and 89.0 (Bolton et al., 2016; Fantaguzzi et al., 2018) (Lynch et al., 2016; Omorou et al., 2016; Sigvartsen et al., 2016; Hourani et al., 2017; Hovsepian et al., 2017; Freire and Ferreira, 2018; Ilhan et al., 2019). However, these studies used different HRQoL scales, and there were differences in population and 
environment. Therefore, future research needs to study the difference between the HRQoL of students in academic and vocational schools.

In addition, $46 \%$ of participants' households had a total monthly income of 5,000 rials; in comparison, the average monthly income of Saudi households in 2018 was 14,823 rials (GaStat, 2018). This is consistent with the results of a Thailandian study that showed children from low-income families are more likely to receive vocational education to improve their chances of finding a job earlier, acquiring the skills needed by employers, and earning high wages early in their careers (Plubplueng and Patmasiriwat, 2019). According to the latest report, more than half of the students have ever attempted cigarette smoking $(51.5 \%)$, compared to less than a fourth of students in the United States $(24.1 \%)$ that detected using the same research tool (CDC, 2019). On the other hand, more than half of American high school students (53.3\%) said they had tried tobacco products (CDC, 2020a). E-cigarettes are the most widely used tobacco product by high school students $(27.5 \%)$, followed by cigars and cigarettes $(7.6 \%$ and $5.8 \%$, respectively) (CDC, 2020a). About 3 in 10 students reported trying two or more tobacco products (29.9\%) (CDC, 2020a). Although we only focused on smoking in this study, there are some differences between our results and those of American students. According to the results of our survey, the proportion of male high school students who have past smoked in Saudi Arabia is (25.5\% to 55.6\%) (Amin et al., 2010; Al Ghobain et al., 2011; Gaffar et al., 2013; Albangy et al., 2019). However, two studies found that the smoking rate among vocational high school students is higher than that of high school students (Wang et al., 2016; Lin and Gebel, 2021).

Moreover, nearly a third of the study respondents currently smoked cigarettes $(30.2 \%)$, compared to nearly 5 out of 100 US students $(4.0 \%)$ (CDC, 2020a). On the other side, about 24 students out of 100 use tobacco products $(23.6 \%)$ (CDC, 2020a). Our results align with Saudi Arabia's smoking prevalence among secondary school students, ranging from $9.72 \%$ to $37 \%$ (Alasqah et al., 2019).

\section{Recommendations and Limitations}

Our research has some limitations. The use of self-reported surveys in this fragile era can lead to inaccurate or exaggerated responses, as well as compositional biases in memory and social criticism. In addition, the results do not apply to all young Saudis. We recommend further investigation to assess the nature of the problem and possible risk factors. In addition, future research including multiple institutions can be conducted.

In conclusion, this study has shown that smoking has a negative impact on HRQoL. Furthermore, those reporting current and past smokers were more likely to report worse HRQoL scores than those who had never smoked. Therefore, smoking cessation should be encouraged for smokers and past smokers among students in the secondary industrial institute in Dammam to change their smoking habits, reduce bad behaviors, and improve HRQoL.

\section{Author Contribution Statement}

Conceptualization, Al-Kalif, M.S.H.; methodology, Al-Kalif, M.S.H.; software, Al-Kalif, M.S.H.; validation, Al-Kalif, M.S.H.; formal analysis, Al-Kalif, M.S.H.; investigation, Al-Kalif, M.S.H.; resources, Al-Kalif, M.S.H.; data curation, Al-Kalif, M.S.H.; writingoriginal draft preparation, Al-Kalif, M.S.H. and Alnasser, A.H.A.; writing - review and editing, Al-Kalif, M.S.H. and Alnasser, A.H.A.; visualization, Alnasser, A.H.A.; supervision, Alghamdi A.A. and Albagmi F.M.; project administration, Alghamdi A.A. and Albagmi F.M.

\section{Acknowledgements}

The authors greatly appreciate the contribution of The Secondary Industrial Institute for helping us in collecting data. Also, we thank Dr. Nuzayhah Ali Almuzaen and Dr. Hussain Ali N Alsalman for translating and revising the Youth Risk Behaviour Surveillance System questionnaire. Moreover, we thank the Institute of Epidemiology, Faculty of Medicine, University of Belgrade, Serbia, for providing the questionnaire and cooperating with us. This study was not funded, the work was performed within the framework of a Master of Public Health thesis. The project of the thesis was approved at the Institutional Review Board of the Department of Public Health, College of Public Health of Imam Abdulrahman Bin Faisal University (PGS-2020-03-418) according to the guidelines of the Declaration of Helsinki.

\section{Conflict of Interest}

Authors declare no conflict of interest in this study. This research received no external funding. The principal investigator can provide the data if requested.

\section{References}

Abdulmohsen Hamdan A-Z, Ayat Roushdy A, Reem Ibrahim A (2015). Intention to quit smoking among intermediate and secondary school students in Saudi Arabia. Asian Pac J Cancer Prev, 16, 6741-7.

Al Ghobain MO, Al Moamary MS, Al Shehri SN, et al (2011). Prevalence and characteristics of cigarette smoking among 16 to 18 years old boys and girls in Saudi Arabia. Ann Thoracic Med, 6, 137-40.

Alasqah I, Mahmud I, East L, et al (2019). A systematic review of the prevalence and risk factors of smoking among Saudi adolescents. Saudi Med J, 40, 867-78.

Albangy FH, Mohamed AE, Hammad SM (2019). Prevalence of smoking among male secondary school students in Arar City, Saudi Arabia. Pan Afr Med J, 32, 156.

Amin TT, Amr MAM, Zaza BO, et al (2010). Harm perception, attitudes and predictors of waterpipe (shisha) smoking among secondary school adolescents in Al-Hassa, Saudi Arabia. Asian Pac J Cancer Prev, 11, 293-301.

Bolton KA, Jacka F, Allender S, et al (2016). The association between self-reported diet quality and health-related quality of life in rural and urban Australian adolescents. Australian $J$ Rural Health, 24, 317-25.

CDC (2018). Health-Related Quality of Life (HRQOL) [Online]. Available: https://www.cdc.gov/hrqol/concept.htm [Accessed 10/07/2021. 
Dube SR, Thompson W, Homa DM, et al (2013). Smoking and health-related quality of life among U.S. adolescents. Nicotine Tob Res, 15, 492-500.

Fantaguzzi C, Allen E, Miners A, et al (2018). Health-related quality of life associated with bullying and aggression: a cross-sectional study in English secondary schools. Eur $J$ Health Economics, 19, 641-51.

Freire T, Ferreira G (2018). Health-related quality of life of adolescents: Relations with positive and negative psychological dimensions. Int $J$ Adolescence Youth, 23, 11-24.

Gaffar AM, Alsanosy RM, Mahfouz MS (2013). Sociodemographic factors associated with tobacco smoking among intermediate and secondary school students in Jazan region of Saudi Arabia. Substance Abuse, 34, 381-8.

Hourani EM, Hammad SM, Shaheen A, et al (2017). Healthrelated quality of life among Jordanian adolescents. Clin Nurs Res, 26, 337-53.

Hovsepian S, Qorbani M, Motlagh ME, et al (2017). Association of perceived weight status and health-related life quality in children and adolescents: The weight disorder survey of the CASPIAN- IV study. Int J Pediat, 2017.

Ilhan N, Peker K, Yildirim G, et al (2019). Relationship between healthy lifestyle behaviors and health related quality of life in turkish school-going adolescents. Nigerian J Clin Pract, 22, 1742.

Jiao WY, Wang LN, Liu J, et al (2020). Behavioral and emotional disorders in children during the COVID-19 epidemic. J Pediatr, 221, 264.

Lin W-H, Gebel M (2021). Education tracking and adolescent smoking: a counterfactual and prospective cohort study. Addiction, $\mathrm{n} / \mathrm{a}$.

López-Nicolás Á, Trapero-Bertran M, Muñoz C (2018). Smoking, health-related quality of life and economic evaluation. Eur J Health Economics, 19, 747-56.

Lynch FL, Dickerson JF, Feeny DH, et al (2016). Measuring health-related quality of life in teens with and without depression. Med Care, 54, 1089-97.

Milic M, Gazibara T, Pekmezovic T, et al (2020). Tobacco smoking and health-related quality of life among university students: Mediating effect of depression. PLoS One, 15, e0227042.

Omorou AY, Langlois J, Lecomte E, et al (2016). Cumulative and bidirectional association of physical activity and sedentary behaviour with health-related quality of life in adolescents. Qual Life Res, 25, 1169-78.

Plubplueng T, Patmasiriwat D (2019). Vocational education choice and fiscal incentive for low-income families. Thammasat Rev, 22, 91-120.

Sigvartsen J, Gabrielsen LE, Abildsnes E, et al (2016). Exploring the relationship between physical activity, life goals and health-related quality of life among high school students: a cross-sectional study. BMC Public Health, 16, 709.

Thorisdottir IE, Asgeirsdottir BB, Kristjansson AL, et al (2021). Depressive symptoms, mental wellbeing, and substance use among adolescents before and during the COVID-19 pandemic in Iceland: a longitudinal, population-based study. Lancet Psychiatry, 2021.

Van den Toren SJ, van Grieken A, Mulder WC, et al (2019). School absenteeism, health-related quality of life [HRQOL] and happiness among young adults aged 16-26 years. Int $J$ Environ Res Public Health, 16.

Vardavas CI, Nikitara KJTid (2020). COVID-19 and smoking: A systematic review of the evidence. Tob Induc Dis, 18, 20.

Wang M, Zhong J-M, Fang L, et al (2016). Prevalence and associated factors of smoking in middle and high school students: a school-based cross-sectional study in Zhejiang
Province, China. BMJ Open, 6, e010379.

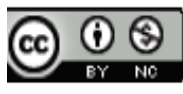

This work is licensed under a Creative Commons AttributionNon Commercial 4.0 International License. 